\title{
Peer influence on children's reading skills: A social network analysis of elementary school classrooms.
}

\section{Citation}

Cooc, North, and James S. Kim. 2016. "Peer Influence on Children's Reading Skills: A Social Network Analysis of Elementary School Classrooms." Journal of Educational Psychology. doi:10.1037/edu0000166.

\section{Published Version}

10.1037/edu0000166

\section{Permanent link}

http://nrs.harvard.edu/urn-3:HUL.InstRepos:32228262

\section{Terms of Use}

This article was downloaded from Harvard University's DASH repository, and is made available under the terms and conditions applicable to Open Access Policy Articles, as set forth at http:// nrs.harvard.edu/urn-3:HUL.InstRepos:dash.current.terms-of-use\#OAP

\section{Share Your Story}

The Harvard community has made this article openly available.

Please share how this access benefits you. Submit a story.

Accessibility 
Running head: PEER INFLUENCES IN READING

Peer Influence on Children's Reading Skills:

A Social Network Analysis of Elementary School Classrooms ${ }^{1}$

\author{
North Cooc \\ The University of Texas at Austin \\ College of Education \\ James Kim \\ Harvard University \\ Graduate School of Education
}

Citation:

Cooc, N., \& Kim, J. S. (2016). “Peer Influence on Children’s Reading Skills: Social Network Analysis of Elementary School Classrooms.” Journal of Educational Psychology. Forthcoming. http://psycnet.apa.org/psycinfo/2016-59626-001/

\footnotetext{
${ }^{1}$ This study was made possible with an Investing in Innovation Fund (i3) grant from the U.S. Department of Education (PR/Award \# U396B100195). However, the contents of this article do not represent the policy of the U.S. Department, and the content is solely the responsibility of the authors.

Acknowledgements: We thank George Farkas, Ha Yeon Kim, and Young-Suk Kim for comments on earlier versions of this article.
} 


\begin{abstract}
Research has found that peers influence the academic achievement of children. However, the mechanisms through which peers matter remain underexplored. The present study examined the relationship between peers’ reading skills and children’s own reading skills among 4,215 total second- and third-graders in 294 classrooms across 41 schools. One innovation of the study was the use of social network analysis to directly assess who children reported talking to or seeking help from and whether children who identified peers with stronger reading skills experienced higher reading skills. The results indicated that children on average identified peers with stronger reading skills and the positive association between peer reading skills and children's own reading achievement was strongest for children with lower initial levels of reading skills. The study has implications for how teachers can leverage the advantages of peers via in-class activities.
\end{abstract}

Keywords: peer effects, social networks, reading skills

Submission date: October 25, 2016 


\section{Educational Impact and Implications Statement}

This study shows that early elementary school children report identifying and interacting with peers with stronger reading skills within the same classroom. Children with low initial reading skills are more likely to identify such peers than high achieving children and those who do so experience higher reading outcomes later on. The study suggests that peer effects may occur through the peer-seeking patterns of children and the direct expertise of their peers. 


\section{Peer Influence on Children's Reading Skills:}

\section{A Social Network Analysis of Elementary School Classrooms}

The influence of peers on student learning and achievement has long been an interest of educators, parents, and researchers. Classroom decisions about student grouping, whether through formal tracking or informal reading activities, are often guided by beliefs about how students interact and learn from each other (e.g., Hong, Corter, Hong, \& Pelletier, 2012). Parents may also make decisions about schools in part due to beliefs about the advantages of learning from high-achieving peers, the benefits of adopting the norms established in these environments, or the value of a diverse population (Kimelberg \& Billingham, 2012; Roda \& Wells, 2013). These beliefs about student learning are supported in extensive empirical research showing that peer interactions and relationships are associated with a range of adolescent behaviors and longterm academic outcomes (Fujimoto, Unger, \& Valente, 2012; Justice, Petscher, Schatschneider, \& Mashburn, 2011; Mashburn, Justice, Downer, \& Pianta, 2009; Sacerdote, 2001; Zimmer, 2003). The extent to which peers matter relative to other family and school inputs is important for educators in addressing disparities in academic achievement and designing appropriate instructional practices. Consequently, numerous studies across disciplines have focused on identifying how peer effects are distributed across schools and whether they matter more for some students than others (e.g., Hanushek, Kain, Markman, \& Rivkin, 2003; Justice et al., 2011).

Although evidence suggests that peers matter in many educational contexts, few studies examine how peers influence one another (see review in Harris, 2010). Part of the challenge is linking theories of peer influence to empirical evidence. Different theories may yield similar or ambiguous predictions of student outcomes, making it difficult to test the mechanisms of peer influence. For instance, peers may have a direct influence through student-to-student interaction 
in learning groups, while an indirect influence may occur via specific norms within a classroom of similar peers. Studies that define peer influence broadly are less able to distinguish the two, which has implications for how to tailor classroom practice. A related challenge is how studies operationalize the concept of peer influence with empirical data. Different measures of peer effect may lead to different findings across studies that can affect policy decisions. Both challenges — theory and measurement-are important to address in order for educators to develop more informed interventions that leverage the benefits of peers (Mashburn et al., 2009).

In this study, we address the theoretical and measurement challenges in the peer influence literature by using a social network analysis approach that more directly identifies who children report talking to and seeking help from in classrooms and assesses whether the average achievement of these peer groups predicts individual achievement. We also replicate and extend previous studies in several ways. Whereas many other studies have used smaller classroom samples to examine peer influence (e.g., Delay, Hanish, Martin, \& Fabes, 2016; Justice et al., 2011), we surveyed over 4,200 children about their peer relationships. This replication, which to our knowledge is the largest to examine peer influence on young children, improves on the generalizability and stability of prior findings. We expanded on the literature by using improved measures of who children report interacting with and the characteristics of those peers to explore the mechanisms through which peer effects may occur. This is important because knowing that children in classrooms with high achievers on average tend to perform better than in classroom with low achievers, as previous research indicate (e.g., Hanushek et al., 2003), is less useful to teachers on a day-to-day basis than understanding the relationships between peers and how students learn from each other. This study addressed whether children reported identifying peers who are strong readers within the classroom, which allowed us to analyze one potential 
mechanism of peer influence. The results have implications for classroom instruction decisions related to structured peer activities and class time for students to work together. Lastly, to better support struggling readers, this study analyzed whether interacting with higher achieving peers is associated with larger benefits for students who have lower initial reading achievement. Finding differential effects for struggling readers provides another way to reduce achievement gaps.

To be clear, throughout the paper and discussion of the methods and results, our use of the terms “peer influence” and "peer effects” refers to statistical associations between the achievement of children and their peers, controlling for confounding factors. We focus on describing these associations in peer relationships and acknowledge here and in the limitation section that the design of the study was not intended to allow for causal inferences about peers. Although we have made efforts to avoid the use of causal language, the terms "peer influence" and "peer effects" in this paper refer only to statistical associations in a non-experimental study. We have retained these terms to be consistent with the research literature on this topic.

\section{Theories of Peer Influence}

\section{Social Contagion}

Studies exploring how peers influence academic outcomes or adolescent behaviors are generally grounded in an "epidemic" or "contagion" theory in which children emulate their peers (Christakis \& Fowler, 2013; Jencks \& Mayer, 1990). For instance, if peers are high achievers who engage in academically oriented habits like studying and homework completion, then students who interact with these peers may adopt those habits and perform better academically (Harris, 2010). The contagion model suggests that these habits maybe absorbed without explicit modeling from peers. This process also implies differential benefits whereby more disadvantaged students gain more from peers who are stronger academically (e.g., Justice, Logan, Lin, \& 
Kaderavek, 2014), while peers who struggle academically may lower a student's own scores. A concern within preschool programs that enroll mostly low-income students is that children are less exposed to peers with school readiness skills who can indirectly provide academic stimulation (Schechter \& Bye, 2007). Studies on children's language growth have found that children with lower initial language skills saw more gains when in classrooms with peers who had higher levels of language development (Masburn et al., 2009; Justice et al., 2011). Related research indicates similar contagion processes occur when examining peer behaviors like smoking (Fujimoto et al., 2012). While these studies provide support of the contagion model, it is unclear how children interact with each other beyond attending the same classroom or school.

\section{Instrumental Model}

In contrast to the social contagion models, psychologists have emphasized the mediating and active role of peer collaboration to enhance the cognitive development of lower-ability children. These theories argue that peers can provide expertise or directly model behaviors and skills that are "instrumental” to academic achievement (Harris, 2010; Ryan \& Shim, 2012). Expert guidance (Vygotsky, 1978; Wood, Bruner, \& Ross, 1976) and observational learning (Bandura, 1977, 1986; Schunk, 1998) are potentially two mechanisms through which peer effects operate. For example, in an experimental study involving pre-school children, Azmitia (1988) found that peer collaboration promoted greater learning than independent work, particularly for novice learners. Peer effects were largely mediated through experts’ guidance in supporting the learning of novices and novices' own initiative in observing, imitating, and learning from experts (Vygotsky, 1978; Ellis \& Rogoff, 1986). Importantly, experimental research indicates that peer effects involve both experts’ direct assistance in supporting novices’ learning and novices’ helpseeking behaviors in learning from experts (Bandura, 1977; Wood, 1980). Observation of peer 
models can raise observers’ self-efficacy beliefs, which in turn may influence learning and achievement (Schunk, 1987; Schunk \& Hanson, 1989). Quasi-experimental research in school and classroom contexts also indicates that lower-ability children experience larger gains in school academic learning from learning in contexts with higher-ability peers (Hanushek et al., 2003; Harris, 2010; Justice et al., 2011). Studies that define peer influence broadly, such as attending a classroom where the average student achievement level is high, are less able to highlight potential mechanisms through which peers influence an individual child's learning.

\section{Homophily}

One empirical challenge in the peer influence literature is separating effects of peers from selection bias. That is, high achieving children may simply identify or interact with peers who also have high levels of academic achievement (Allermatt \& Pomerantz, 2003; 2005). Homophily is the social phenomenon and tendency of individuals to affiliate with others who share similar attributes (Kandel, 1978). Such affiliations have been observed in terms of children’s externalizing behaviors (Hanish, Martin, Fabes, Leonard, \& Herzog, 2005) and academic motivation (Ryan, 2001), as well attributes like gender and race (Vu \& Locke, 2014). If children affiliate with similar friends then they are likely to act or behave in similar ways, thus making it difficult to distinguish peer influence-via social contagion or instrumental effects— from homophily. Children may have higher academic achievement not because of peer effects of learning from each other but because of other unobserved traits that led them to interact. A robust literature indicates that peer effects via observational learning may depend on perceived similarity between model and observer in terms of academic competence and skills (e.g., Schunk, 1987). A key question is whether children, particularly those with lower achievement, identify and benefit from associating with peers with higher achievement. Identifying this social 
network pattern in classrooms would provide stronger evidence of peer influence on achievement, even if children are likely affiliating with similar peers on other dimensions.

In general, numerous theories and mechanisms are involved when examining peer influence. In studies that specifically examine language skills and other academic outcomes (e.g., Justice et al., 2011; Mashburn et al., 2009), the role of peer expertise and assistance is assumed but rarely explored. However, examining the mechanism is important if we are to understand how peers matters in relation to helping children develop skills like reading. For instance, whether it is sufficient for school officials to know that children are around peers who are strong readers or in a classroom with similar readers is important for instructional practice. Theories that emphasize the role of peer collaboration should ideally explore whether lower-ability readers identify higher-ability readers, and whether peer effects depend on children’s individual skill.

\section{Measuring Peer Influence}

Although studies make implicit assumptions about the social contagion and instrumental models that inform how peer influence is manifested in school settings, part of the issue is how researchers measure peer influence. Measurement is important not only for accuracy but also the type of inferences that one can make about peers. In many empirical studies, particularly those using large student administrative records or secondary data, peer influence is typically operationalized as the average achievement level of students within a given classroom (e.g., Hanushek, Kain, Markman, \& Rivkin, 2003; Henry \& Rickman, 2005; Justice et al., 2009). The assumption is that a classroom of high achieving classmates contributes an overall peer effect on a given student, such as higher reading scores. The classroom average is more aligned with the social contagion model of peer influence, but it overlooks the smaller and more informal social networks that children may form with one another based on proximity or shared interests. In the 
case of developing reading skills, it is likely through these more proximal networks that peers may influence student achievement, especially if experts assist novices by providing corrective feedback on literacy tasks (Fuchs, Fuchs, Mathes, \& Simmons, 1997; Greenwood, Delquadri, \& Hall, 1989) or novices ask experts for help, or learn by observing experts (Bandura, 1977).

Examining the instrumental model of peer influence requires a different measure of peers. In sociology and public health, this approach typically involves identifying all the peers of each individual or specific peers, such those from whom one seeks advice or academic help (Scott \& Carrington, 2011). Rather than using a class average, the peer influence variable is the average score of only the peers who were identified for each student (Frank et al., 2008). Although surveying young children about peer relationships can be a difficult procedure, the measure provides a more precise summary of who children interact with regularly and proximal peers. For instance, if struggling readers are able to identify peers who are strong readers and seek them out for help, then this type of social network measure is potentially more helpful in assessing how peers may influence achievement. Unfortunately, studies using the aggregate classroom or school achievement level of children are unable to examine this potential mechanism.

\section{Why focus on peer influence on early reading skills?}

The National Assessment of Educational Process (NAEP), a low-stakes but representative assessment of students across the U.S., indicated in 2013 that only $42 \%$ of fourth graders score at or above proficient in reading (National Center for Education Statistics, 2013). Nearly $20 \%$ of students score below basic and can be considered struggling readers who lack the ability to comprehend written text at grade level. These trends are concerning since basic reading and literacy skills are critical for acquiring content knowledge and strongly predict future 
outcomes like graduation, employment, and college (Achieve Inc, 2005; Kamil, 2003; Snow \& Biancarosa, 2003). Although school intervention efforts can improve children’s cognitive and reading skills (see synthesis in Edmonds et al., 2009), social scientists have theorized and found that peer composition is strongly associated with individual children's reading development in the elementary grades (Entwisle \& Alexander, 1994; Kinderman, 2007).

Experimental research indicates that peer collaboration is a particularly powerful and malleable factor that can impact children's early literacy development. For example, the Peer Assisted Learning Strategies (PALS) utilize the peers of struggling readers as coaches to help children acquire reading skills (Fuchs et al., 2000; Fuchs, Fuchs, \& Burish, 2000). Students are put in pairs geared towards their individual needs, rather than a single teacher-directed activity that may not address the reading challenges of most children. In shifting instruction from teachers to students, these strategies can be both effective and efficient in helping struggling readers. Results from multiple replication experiments have shown that PALS improves a range of early literacy skills, including children's phonological awareness, word reading ability, and oral reading fluency outcomes (Lemons et al., 2014), which are moderately correlated with later reading comprehension outcomes (Good et al., 2011). The role of peers for struggling readers is particularly important since they appear to benefit more from exposure to peers with stronger literacy skills (Mashburn et al., 2009; Justice et al., 2011).

Although peer reading interventions like PALS require some formal structure in matching students, most center on the basic premise that peers matter and struggling readers can develop literacy skills when interacting with certain peers. In other words, these interventions are a highly structured form of the social contagion and instrumental models of peer influence. However, the peer effects literature suggests that these processes are also like to occur naturally 
and informally, while still accruing benefits for students. Understanding the extent to which this happens can be helpful for teachers in designing practices that leverage the skills and advantages of peers. Furthermore, although the mCLASS-DIBELS Next is used to group students with similar needs, teachers can apply the same principles to create heterogeneous groups if students learn better from peers from diverse achievement backgrounds.

\section{Present Study}

The consistent finding that peers appear to influence the academic achievement of children is not new, but the present study extends the literature in several ways. First, we assessed how peers may influence reading skills by examining the characteristics of peers. If peers matter because they provide access to expertise then evidence that students identify and interact with these peers can provide support for this theory of peer influence. Although students may benefit from simply learning in the same classroom as certain peers and observing similar norms, we focused on their peer interactions and own agency in developing reading skills.

Our second contribution focuses on using more direct measures of peer influence when examining its effects on academic achievement. Prior studies often operationalize peer influence as the average achievement of level of students within a classroom (e.g., Hanushek et al., 2003; Justice, et al., 2011; Mashburn, et al., 2009). However, if peer effects manifest through child-tochild interaction and the transmission of specific behaviors or skills, then the average classroom achievement is a less appropriate measure of peer effect. Children are likely to have smaller social networks within the classroom consisting of proximal peers who they interact with on a regular basis. In this study, we surveyed second and third graders about who they seek help from or go to when discussing reading. The reading outcomes for these peers were identified and used to assess how they may relate to a child's own reading achievement. 
A third contribution of our study is we improve on the generalizability and scope of previous research on peer effects with young children. One of the main challenges with social network analysis is the data collection procedures can be labor intensive. Respondents are required to complete network surveys about all the peers they talk to, a task that can be difficult cognitively for younger children. In this study, we collected network surveys from more than 4,000 second and third graders across nearly 300 classrooms in 41 schools and at two time points. To our knowledge, this is one of the largest studies to assess peer influence directly from the self-reports of young children. In focusing on early elementary students, the study also expands on previous studies examining peer influence in preschool (e.g., Justice, et al., 2011) and upper elementary school grades (Hanushek et al., 2003).

In summary, our first research aim is to assess patterns in peer reading networks and examine whether peer reading achievement predicts children’s reading achievement after controlling for prior academic achievement and individual background characteristics. Our second aim is to examine whether the influence of peers may depend on a child's individual reading ability. If struggling readers interact with peers who are stronger readers, then the contagion theory argues that these children are likely to emulate the behaviors of their peers (e.g., reading more) and become better readers over time (Harris, 2010; Hoxby \& Weingarth, 2005). Research shows that stronger peers may serve as a protective factor for low-achieving achieving students (Hanushek et al., 2003; Justice et al., 2011; Masburn et al., 2003). We asked the following three research questions:

1. To what extent do children report identifying peers who are stronger readers for help or to talk about reading? 
2. To what extent does the reading achievement of peers predict the reading achievement of children, controlling for individual and classroom factors?

3. To what extent does the relationship between peer reading achievement and children’s reading achievement depend on children’s initial reading level?

\section{Methods}

\section{Study Context and Participants}

We employed secondary data from a larger longitudinal study of an experimental reading program to reduce reading loss among low-income elementary school children (Kim, Guryan, White, Quinn, Capotosto, \& Kingston, 2016). The initial data represent 6,383 children from 7 districts and 59 schools in North Carolina. Data collection began with 3,433 second-grade children and 2,950 third-grade children in 2013, many who were primarily from low-income (77\% received free or reduced price lunch) and racial minority households (76\%). About 17\% spoke a non-English language at home. As part of the summer intervention, consented children in the spring were randomly assigned to receive reading lessons during the last weeks of school and 10 self-selected books in the mail each week of the summer. Books were selected based on student preference and reading level from a reading catalogue. Students in the control group participated in math lessons in the spring, but received books in the following fall. Reading assessments from the Iowa Test of Basic Skills (ITBS) were administered to all students before and after the full intervention to measure the impact on reading loss over the summer.

For the present study we used a final subsample of 4,215 total second- and third-grade students who participated in schools that used the mCLASS-DIBELS Next as a formative assessment of early reading skills, beginning in fall 2012 through spring 2013. In contrast to the ITBS that was administered to all students before and after the summer, this subgroup of students 
with reading scores on the mCLASS-DIBELs allowed us to assess reading achievement and peer effects during the school year. We focus on the fall to spring period, Time 1 (T1) to Time 2 (T2), to more fully capture when students are together. We note that the present study used assessment data collected before the randomized summer reading intervention, which eliminates potential spillover effects from the latter. The composition of the original and analytic subsample is comparable, with the latter having a slightly higher percentage of students on free or reduced price lunch. In the top half of Table 1, we summarize the characteristics of students in our study.

In the bottom half of Table 1, we provide a summary of the classrooms and teachers. On average, classrooms served nearly 14 children with parental consent to participate in the study. The teacher staff was predominantly White females, comparable to most schools in the U.S. (Goldring, Gray, Bitterman, Broughman, 2013), with an average age of 38. The teachers came from moderately competitive undergraduate schools according to the Barron ranking of universities. Due to the limited number of available classroom and teacher measures, we use the fixed effects of classrooms to control for unobserved factors that may influence children’s reading achievement, in addition to children's peers.

\section{Measures}

Children's literacy skills. Our main reading outcome comes from the Dynamic Indicators of Basic Early Literacy Skills (DIBELS), an early literacy assessment similar to others like the Early Grade Reading Assessment (EGRA) commonly used in numerous countries (Dubeck \& Grove, 2015). The DIBELS consists of a set of procedures assessing early literacy skills from kindergarten through sixth grade. These tests were designed to serve as one-minute fluency measures of early literacy and reading skills in the following areas: sound fluency, phoneme segmentation fluency, letter naming fluency, nonsense word fluency, oral reading 
fluency, and reading comprehension (Kaminski et al., 2008). Participating schools used a software version called mCLASS: DIBELS Next that provides instant analytics on students, such as progress towards benchmark goals, information for instructional lessons, and recommendations for improvement. Teachers assessed their own students in these reading areas using the mCLASS: DIBELS Next on a laptop or iPad, and we used results from the fall 2012 and spring 2013 assessments as Time 1 and Time 2 measures, respectively.

Although the DIBELS provides subscale scores in the literacy areas assessed, we used a composite score that combines the different skills. The composite score (Good et al., 2011) provides a more comprehensive and reliable assessment of children's early literacy skills that is moderately correlated with standardized tests of reading comprehension (e.g., $r=.73$ between DIBELS composite and the Group Reading Assessment and Diagnostic Evaluation reading test). Depending on the grade level, the composite score may include up to six fluency areas. For the second grade assessment, the composite score consisted of measures of nonsense word fluency (i.e., basic letter-sound correspondences) and oral reading fluency (i.e., timed passage reading and retell). For the third grade assessment, the composite score included measures of oral reading fluency and reading comprehension, which entailed reading a passage and selected appropriate words for omitted text. Due to differences in the reading content covered in the DIBELS by grade level, we present the model results and analyses separately for grades two and three.

Reliability estimates (alternate-form, test-retest, and inter-rater) of the composite ranged from 0.88 to 0.98 across grades. Assessments of validity (content, criterion, and discriminant) with other reading assessments for separate reading components and the composite indicated that the results were at appropriate levels (see technical manual in Good et al., 2011). The DIBELS scores are summarized by both grades and time periods in Table 1. 
Peer Reading Skills. We created a proxy for peer reading skills by first identifying the peers of each student. In the spring we administered paper and electronic surveys to children about their book preferences for the summer intervention. The survey also included a question about the children's peers that asked, "Who do you talk to about reading or, to get help, in your class?” We combined talking with someone and asking for help since research shows that the two tend to be highly correlated ( $r=.87$ in Frank, Zhao, \& Borman, 2004). That is, the peers that one frequently talks to also tends to be the peers that one seeks advice from. Children were asked to write the names of up to five peers in their class and instructed that it was not necessary to fill in all five spaces, a similar free-recall strategy used in the General Social Survey (Smith, McPherson, \& Smith-Lovin, 2014) and Social Networks and Friendship Survey (Cairns, Cairns, Neckerman, Gest, \& Gariepy, 1988). Based on the results of a pilot study using the survey questions with two classrooms, we did not include a class roster of names for children to choose from in order to reduce the length of the survey (Marsden, 2011). A downside of imposing a limit is it can encourage children to cite additional peers to reach the maximum or limit the true number of peers. We found some evidence of this pattern as about $40 \%$ of children cited five peers, suggesting that some children may have needed more than five spaces while others may have cited additional peers to reach the limit. Unfortunately, the direction and type of measurement bias are difficult to determine in this case. We discuss these limitations in the discussion section but our approach was a compromise between survey length and identifying children's peers. The survey itself was administered in class with a response rate of $97 \%$.

The matching was completed using a computer database that contained the names of surveyed students for each corresponding homeroom class. All students stayed with their homeroom for literacy and regular instruction. The peer names that students listed on their 
survey was then matched to the names in the class roster. Sometimes there was an exact match with the name while other times there were misspellings. For example, a student might spell “Jacob” as “Gacob.” In cases where the misspellings were obvious, we matched the student to the peer in the database. For names that were illegible or not on the homeroom list (i.e., students may have listed peers in other classrooms), we coded the name as “unknown”, which made up about $11 \%$ of all reported peers. We excluded these peers from analyses since their information, such as reading skills, could not be linked to students. About $14 \%$ of students cited no peers (i.e., 0 or unknown names), 15\% for 1 matched peer, 14\% for 2 peers, 14\% for 3 peers, $17 \%$ for 4 peers, and $25 \%$ for 5 peers. We note that the $25 \%$ for 5 peers here differs from the $40 \%$ cited previously, which was based on 5 total peers regardless of whether the peers' names were legible and could be matched in our records. We conducted a sensitivity analysis comparing students who did not cite any peers to those who cited at least one. Results indicated no statistically significant differences between the two groups in terms of academic achievement, race, and ELL status. Students who cited no peers were less likely to be female (42\% to 52\%) and receiving free lunch (76\% to $82 \%)$ than students who cited at least one peer.

We assumed that the peers a child identified as someone to talk about reading or acquire help from in the spring survey (T2) were the same peers they interacted with throughout the school year. Although peer groups are likely to change across years, these social networks are more stable when students are interacting in the same class during the year, especially for young children (Ryan \& Shim, 2012). In contrast to asking children about their peers in the fall (T1) when they may not know each other well, the spring survey is likely a more accurate measure of children's peers since they would have spent nearly the entire school year together. Once the peers of each child from the spring survey were identified, we linked the fall DIBELS scores to 
each peer. Similar to other studies (Justice et al., 2011; Mashburn et al., 2009), we used the fall scores of peers as a baseline or initial measure of peer influence. The number of peers with valid scores ranged from none (9\%) to five (25\%) with an average of about three per child. Finally, we averaged the DIBELS scores across peers for each child to estimate the reading level of their peers, which serves as our measure of peer influence. We also explored using the highest score from peers and the score of the first peer cited as a measure of peer influence. Because these measures produced similar results (see supplemental appendix), we used the average due to its reliability. In Table 2, we present the average peer score per child by grade level.

Indegree. For each child, we calculated the number of times other children cited him or her as someone to talk about reading or seek help from. Students who have many ties, also known as indegree centrality, are considered more prominent in the network or possess specific skills that other children seek. In this study, we expected students with high indegree measures to also have stronger reading skills (Hannenman, \& Riddle, 2011).

Child Characteristics. We included four student characteristics in our analyses: gender, race/ethnicity (Black, Hispanic, White, and other), English language learner, and free or reduced priced lunch status. Controlling for these potential confounders can reduce the bias when estimating the relationship between peer effects and reading achievement. The background information comes from administrative records at the child's school.

Teacher and Classroom Characteristics. Although we were interested in estimating the influence of peers on children's reading skills, peer effects may also be confounded with teacher quality or classroom specific traits. Consequently, we included the fixed effects of classrooms in our models, which restrict our analysis of peer effects within classrooms, thereby controlling for all observed and unobserved factors (i.e., teacher and classroom characteristics) that may 
confound the relationship between reading achievement and peers. We caution that the fixed effects and student control variables do not result in causal estimates of peer effects but help reduce selection and missing variable bias.

\section{Analysis}

To address our first research question about whether children identify peers who are stronger readers for help or to talk about reading, we conducted a descriptive analysis comparing the average achievement of children and the peers they identified. The expectation was that children would be likely to identify peers of similar or higher reading levels when seeking help about reading. We also examined the achievement level of children who were most frequently nominated by their peers as someone to seek help from or talk about reading, also known as the indegree measure (Scott \& Carrington, 2011). Theoretically, children with high indegree should have higher achievement since other children are seeking them more frequently. The indegree measure is another way to assess whether children are identifying expert peers.

To address our second research question about whether peers influence children's on early reading skills, we fit the following regression model:

$$
S R_{i j k}=\alpha+\beta_{1} F R_{i j k}+\beta_{2} F R_{i j k}^{P E E R}+\gamma X_{i}+\delta_{j}+\varepsilon_{i j k}
$$

where $S R$ is the spring DIBELS reading score (T2), FR is the fall DIBELS reading score (T1), $F R^{\text {PEER }}$ is the average fall DIBELS reading score (T1) of student $i$ 's peers in classroom $j$ of school $k, X$ is a vector of student characteristics with $\gamma$ as the parameter estimates, $\delta$ is a vector of classroom fixed effects, and $\varepsilon$ is the error term. The model predicts the relationship between peer reading achievement in the fall and a student's spring reading achievement, while controlling for the student's own prior reading ability in the fall, student demographic characteristics, and classroom-specific effects on reading. 
As an alternative strategy we considered fitting a multilevel model with students nested within classrooms and adding classroom-level covariates. However, we chose Model (1) because the classroom fixed effects allowed us to control for all observed and unobserved classroom factors that may confound the relationship between student and peer achievement. For instance, in classes where students learn better from their peers, the teachers may also be using specific instructional practices. The classroom fixed effects in $\delta$ control for these differences in teaching across classrooms. Another concern was variation in reading scores due to school-level differences (e.g., curriculum). However, preliminary analyses with a three-level model (students nested within classrooms within schools) indicated that less than 5\% of the variation in reading scores was attributed to school differences. Of interest in Model (1) is $\beta_{2}$, which represents the estimated effect of peer reading achievement on student $i$ 's spring reading scores. A positive parameter estimate suggests that students with peers who have high reading achievement tend to also have higher reading achievement.

To address our third research question about whether peer influence may differ for students at different levels of initial reading achievement, we supplemented Model (1) with an interaction term between student $i$ 's fall reading score and student $i$ 's peer fall reading score:

$$
S R_{i j k}=\alpha+\beta_{1} F R_{i j k}+\beta_{2} F R_{i j k}^{P E E R}+\beta_{3} F R_{i j k} \times F R_{i j k}^{P E E R}+\gamma X_{i}+\delta_{j}+\varepsilon_{i j k}
$$

The key parameter of interest is $\beta_{3}$. A negative value indicates that the association between peer and children reading achievement is stronger for students with lower initial reading scores than students with higher initial reading achievement. Conversely, a positive value means that students with higher initial reading scores tend to have higher achievement when they associate with peers who are also high achievers. We conducted all analyses in Stata 14.0. 
We identified missing data primarily for children’s average peer reading scores (20\%). Missing peer reading scores was due to students not completing the social network section of the survey $(11 \%)$ or if we were unable to match peers to their scores (9\%). To reduce potential bias from the missing data, we imputed values using chained equations in Stata 14.0 (i.e., 'mi impute chained' command) that pool together results from 20 imputed datasets (StataCorp, 2013).

\section{Results}

\section{Research Question 1: Peer Reading Network Patterns}

We begin with a descriptive summary of who children go to about reading or help. Table 2 displays children's fall DIBELS scores by quartile and the scores of the peers they identified. The results indicate that children with lower reading achievement tended to identify peers who had higher average reading scores. For instance, in the upper panel for grade two, children in the first quartile had an average score of 57.5, while the average of their peers’ scores was nearly three times higher at 157.2, $t(1048)=33.2, p<.001$. On the other hand, we note that children in the fourth quartile with high initial reading scores did not tend to identify peers with similar or stronger achievement. Indeed, high achieving children in the fourth quartile $(M=254.1, S D=$ 35.0) tended to interact with peers with lower reading scores $(M=193.0, S D=54.1)$. One possible explanation is that there may be fewer other high achieving students in the same classroom. Overall, in the grade two sample the average fall score for children is 158.3 while their peers scored an average of 176.5, or about a 0.27 SD difference. We see similar patterns in who children identify for help in grade three in the lower panel.

Another way to examine whether children are identifying strong readers is to focus on the achievement level of children who are in "high-demand" according to their peers. These are children that others cited as someone to go to for help with reading. The indegree measure in 
Table 3 indicates the number of other children who cited child $i$. For instance, about $27 \%$ of second graders had four or more peers cite them as someone they go to for help with reading. One contribution of the indegree measure is we can identify children who are experts according to their peers, which may differ from what teachers report. The results show that, across grades, children who were in higher demand tended to also have higher reading achievement than children who were identified less frequently by their peers. For instance, the average score of second graders with an indegree of 7 or more is 325.4, compared to 238.5 for children with an indegree of only 1 , which indicates that children were identifying peers who were strong readers. The correlation between student indegree and DIBELS score is moderate $(r=.24, p<.001)$.

In Figure 1, we display the social networks of two large classrooms (relative to the average classroom size of about 14 students) with the node (circle) size representing children who were strong readers based on peer nomination. We chose the two classrooms because the size permitted a better display of the network. The direction of the arrows indicates that students in each classroom identified a group of peers who others also cited as someone to go for help in reading. Children who were strong readers were also more central within the classroom. Overall, these descriptive results indicate that the children tended to identify peers who were stronger readers when they sought others to talk about reading or ask for help. Although homophily on other student traits cannot be ruled out, the descriptive results suggest that children are not necessarily affiliating with peers who have similar reading levels.

\section{Research Question 2: Peer Effects on Reading Achievement}

In Tables 4-5, we present results from regression models that predict the relationship between peer effect and student achievement separately for grades two and three. Each successive model includes additional covariates to reduce the bias when estimating peer effects, 
with classroom fixed effects controlling for unobserved differences across classrooms. Separate analyses with unconditional multilevel models justified this concern since the intraclass correlation indicates that about 18 to $24 \%$ of the variation in student scores for each grade is attributable to classroom differences. We initially identified a moderate correlation between fall peer achievement and spring student achievement $(r=.23, p<.001)$. In Model 1 , however, this relationship is no longer statistically significant when controlling for students' own prior scores in the fall $(\hat{\beta}=0.021, p=.525)$. Results in Model 2 indicate no racial disparities in reading achievement controlling for prior achievement. Female students tended to score higher, while ELLs and students receiving free lunch scored lower than their counterparts. The effect of peer achievement remains statistically insignificant. We found similar results when controlling for classroom fixed effects in Model 3. The lack of a relationship between peer and student achievement is not surprising since peer scores were correlated with students' fall scores ( $r=$ .26). However, this suggests that the added value of peers is removed when accounting for prior achievement. We detected a similar pattern when examining peers for grade three in Table 5.

\section{Research Question 3: Differential Peer Effects for Struggling Readers}

In our third research question, we examined whether there is a stronger relationship between peer effect and student achievement for students who were struggling initial readers. In Model 4 of Table 4, the interaction term between peer achievement and initial reading achievement supports this hypothesis $(\hat{\beta}=-0.0009, p<.001)$. The effect of peers differs by initial reading achievement, even when controlling for prior achievement and classroom fixed effects. The negative interaction indicates that children with lower initial test scores benefit more around peers with higher scores than students who were already strong readers. This finding is consistent for third graders in Table $5(\hat{\beta}=-0.0007, p<.001)$. We display this interaction in 
Figure 2 for second graders. Similar to Justice et al. (2009), we define high and low initial readers as students with initial fall reading scores one standard deviation above and below the mean for all students, respectively. Due to a slight skew in the peer achievement variable, we used the $25^{\text {th }}$ and $75^{\text {th }}$ percentile to define peers of low and high reading achievement, respectively. Figure 2 shows that among students with low initial achievement in the fall, those who reported interacting with high achieving peers scored about 10 points higher on average or an effect size of about $0.09 S D$ than students who are strong readers initially $(F=8.98, p=.002)$. The effect size is comparable in magnitude to estimates found in similar peer influence studies (e.g., Mashburn et al., 2009; Justice et al., 2011). Students with high initial achievement perform about the same in the spring, regardless of whether they identified peers with low or strong reading skills $(F=2.11, p=.148)$. We see similar trends in Figure 3 for third graders, except high initial achievers scored significantly lower when around peers who are also high achievers. This is consistent with theory and research suggesting that highly skilled students may be less responsive to peer achievement (Hanushek et al., 2003).

\section{Discussion}

Due to the importance of early reading skills for later academic achievement and learning, the primary goal of this study was to examine how peers may influence students' reading skills. Although prior studies have consistently found that peers matter on a range of behavioral and academic outcomes, the theory and mechanisms through which this occurs are often overlooked. This study expanded on previous studies by directly asking a larger sample of young children across multiple classrooms and schools about the peers they talk to about reading or seek help from. Furthermore, we examined whether children reported identifying stronger readers for help and whether children experienced higher reading achievement when they 
identified stronger readers. A better understanding of how students report interacting and affiliating with each other is important for educators in designing practices and policies that leverage the advantages of peers. The extent to which children can identify and benefit from stronger readers has implications for teaching strategies and group activities.

\section{Identifying Strong Readers}

Our results show that across the entire sample students on average tended to report identifying peers with stronger reading achievement when asked about whom they talk to or seek help from about reading. This is important since help-seeking skills in particular contribute to student motivation, learning, and later achievement, particularly in early adolescence (Karabenick \& Newman, 2006). In contrast to prior studies that have shown that lower achievers are less likely to ask for help when needed (Ryan \& Shim, 2012; Ryan \& Shin, 2011), the present study found that students with low reading achievement tended to report interacting with peers who were stronger readers. One possible explanation for the difference in results is previous studies examined students’ network behaviors based on teacher self-report, often using an overarching question about whether a student possessed appropriate help-seeking skills. The current study surveyed students directly and used social network analyses to examine their peers. Although both approaches have strengths and weaknesses, one advantage of student self-reports is they may capture peer relations within and outside the classroom that teachers may not notice. We also found that students frequently sought by peers tended to have much higher reading scores, suggesting that children in the study were effective in identifying expert readers in their class. While students on average were more likely to identify stronger readers, high achieving children tended to identify peers with lower achievement scores. For high achieving children (upper quartile), this pattern is likely due to having fewer high achieving peers in the same 
classroom. Another possibility is that these are peers they affiliate with for social reasons rather than academic, which may confer less advantages on standardized assessments.

If children are consistently identifying peers with higher reading achievement to discuss reading or for help, particularly low-achieving children, one question for teachers is whether peer support can be more efficiently distributed. Our indegree measure in this study indicates that certain students within a classroom are frequently sought by peers. Although students may be effective in identifying peers who can help, teachers may need to provide some structure to ensure that some children are not potentially overburdened. Another implication of this finding is that teachers may want to more formally prepare children who are in "high-demand" to work with peers. This is consistent with research showing that, in addition to encouraging children to seek help or talk with peers about work, teachers often need to provide more guidance for positive feedback exchanges (e.g., Ryan \& Shim, 2009). Naturally the focus has been on assisting struggling students but high-achieving peers can also assist with the process. Research on peer-mediated instruction (PMI) shows that students can be trained to effectively tutor each other or work together as partners, particularly for struggling readers across grade levels (Maheady, Harper, \& Sacca, 1988; Pyle, Pyle, Lignugaris-Kraft, Duran, \& Akers, 2016). Teachers can develop basic PMI routines involving verbal rehearsals of specific skills and stepby-step feedback from the tutor (Fuchs et al., 1997; Fuchs et al., 2000).

\section{Peer Influence on Achievement}

Our results indicate that peer reading achievement is positively associated with children's own achievement but the relationship is not statistically significant after controlling for prior reading scores and background characteristics. In other words, peer effects are in part related to how strong readers tend to identify peers who also have strong reading skills or other similar 
characteristics and vice versa. The unique contribution of peer reading achievement is particularly difficult to detect when accounting for children's fall scores. However, we identified a small but significant interaction between peer reading achievement and children's initial reading achievement that indicated children with low reading scores appeared to benefit more from affiliating with stronger readers than children with high initial achievement. The finding that peers play a role in children's academic achievement is consistent with other recent studies examining preschoolers (Mashburn et al., 2009; Justice et al., 2011), adolescents (CalvoArmegnol, Patacchin, \& Zenou, 2009), and primary school students (Hanushek et al., 2003). This pattern of peer interaction among children is also found in experimental research indicating that peer effects may manifest as novices identify experts and learn through observation (Bandura, 1977). Furthermore, peer collaboration is a context through which experts may provide direct assistance to novices (Bruner, 1975). Although our study cannot pinpoint the mechanism through which peer effects operate, our results suggest that struggling readers tend to report talking to or seeking help from expert peers, and these children appear to benefit from affiliating with high achieving peers. This is consistent with research indicating that the functional value of a peer depends on a child’s perceptions of a peer's competence (e.g., Schunk, 1987). Children are more motivated to pattern their behaviors after peers who perform successfully than to emulate less competent peers.

Similar to studies that have examined peer influence for highly skilled students (Justice et al., 2011; Hanushek et al., 2003), we found that peers mattered less for high achieving readers. The reasons for why this is the case has been less explored in research. Most prior studies used the classroom average achievement as a proxy for peer achievement, which overlooks specific patterns of interactions between students. One potential reason for the null effect is that high 
achievers in these classrooms simply have fewer opportunities to learn from others of similar skills and, instead, may spend more time helping low achievers. The current study supports this hypothesis as high achieving readers tended to affiliate with peers with lower scores, which may have negative spillover effects whereby struggling students may pull down their scores (e.g., Fletcher, 2010). Furthermore, the high achievers were likely talking about reading with peers, as opposed to receiving help or expertise during such interactions.

Whereas many previous studies on peer influence assume that children adopt the behaviors or norms of a classroom or peer group (e.g., Mashburn et al., 2009; Justice et al., 2011; Schechter \& Bye, 2007), the results in this study, based on student self-report, supports theories that peers matter because they can provide reading expertise or motivation. The findings reinforce policies and practices that aim to structure classrooms such that students have access to peers of different academic achievement levels. More importantly, the findings highlight the agency of children in interacting with peers who are strong readers. This indicates that while having access to high achieving peers matters, students are also successfully identifying them as well. Thus, classroom group or pair activities should be flexible enough to allow students to interact with peers of their choosing. Of course, raising the overall achievement of a classroom is another way to ensure that more children have access to peers who are stronger readers and can provide help. For those who are already strong readers, this also allows them more opportunities to consult with peers with similar achievement than before (as found in this study).

\section{Implications}

The findings presented here show that peer reading skills make a small but important contribution to children's reading skills, especially for those who are struggling readers. One implication is the findings support the use of peer-mediated interventions like PALS that pair 
students according to reading levels and provide opportunities for self-directed learning. These practices allow students to receive corrective feedback in a timely manner and engage in and respond to practice exercises (Hattie \& Temperly, 2007). Policymakers and educators should also recognize the mechanisms through which peers matter to improve on classroom activities. The finding that children on average reported identifying and interacting with peers who are stronger readers does not imply that the matching of peers in structured programs like PALS is unnecessary. Instead, schools with limited resources may benefit from a mix of strategies that include providing children with classroom opportunities to engage with peers on their own (i.e., unstructured), or directly pair students who would benefit from each other.

The conclusion that struggling readers benefited more from interacting with peers of higher skill is particularly relevant for schools addressing large disparities in reading achievement. Although other targeted interventions and strategies are capable of assisting struggling students (e.g., Edmonds et al., 2009), peers can be an efficient method that reduces the many demands placed on teachers, freeing them to focus on other instructional planning. Peer tutoring strategies have also been reported as effective across content areas and for students with disabilities or in special education settings (Klinger \& Vaughn, 1996). This study suggests that a better understanding of children's peers is important for their social and academic development. High achievers, for instance, may need more opportunities to interact with similarly skilled peers in order to benefit academically. While we acknowledge that teachers in this study and elsewhere are likely using these strategies to some degree, the findings provide further support of their usage when considering tradeoffs or targeting specific academic outcomes.

Teachers should also consider the importance of children's network structures and how that may benefit certain students. Children identified peers who they reported talking to or 
seeking help from but they are part of larger social network. According to social network theory, access to information, support, and other resources for individuals may depend on children's location within the network (Daly, 2010). That is, some students may have more favorable positions that permit easier access to high achieving students. Although the peer networks identified in this study were informal, teachers may consider ways to structure the classroom such that all children may feel more connected to each other. Indeed, the classroom network examples in Figure 1 suggest that some students may have more access to peers with stronger reader achievement while others are more isolated. Teachers should monitor these peer relationships, breaking up those that inhibit peer learning while supporting those that foster beneficial interactions to maximize opportunities for positive peer effects.

\section{Limitations and Future Directions}

There are limitations to the study that also provide several avenues for future research. First, the peer effects identified in this study are not causal. Experimental research is needed to better isolate peer effects from issues related to selection bias, and to identify the specific mediators (e.g., expert guidance, observation learning) through which peers influence the learning of individual children (Azmitia, 1988). Although we controlled for prior reading skills, student demographics, and classroom fixed effects, students who interact with strong readers are likely different in other unobserved ways that can confound the relationship between peer and student reading skills. Struggling readers who identify and interact with high-achieving peers may also have strong social skills or higher motivation that affects achievement.

Second, while the study provides insight into possible mechanisms through which peer effects may manifest, the data cannot address the type and quality of interactions among students. For instance, when students reported talking to or seeking help about reading from 
peers, it is unclear whether this occurred as a tutee and tutor relationship. Furthermore, while identifying peers with stronger skills is important, certain types of interactions may be more conducive to learning. Our understanding of peer interaction is also limited to student self-report, so whether children actually sought help from the peers they identified is not captured with our data. Recent studies using classroom observations of children provide a promising way to better identify peer relationships and the type of exchanges that occur between peers (Martin et al., 2013; DeLay, Hanish, Martin, \& Fabes, 2016). Results from these studies using observations are consistent with this study and others using self-reported data. Delay et al. (2016), for instance, observed preschool children's peer interaction partners several times a week over one year and found that children's preschool competency was influenced by their peers' levels of competency. A related issue is children may not necessarily be identifying peers because of their strong reading skills but peers who are more popular within the classrooms. The implication is that interacting with popular peers and adopting similar prosocial norms may benefit struggling readers. We note that the study did find that students on average tended to identify peers with stronger reading achievement. To the extent that achievement and popularity are highly correlated, which some research suggests (e.g., Meijis, Cillesssen, Scholte, Segers, \& Spijerkman, 2010), this confounding effect may be attenuated and less important if students are still interacting (based on self-reports) with high achievers. Teacher observation of children’s peer networks is needed to untangle whether children are identifying peers based on achievement, popularity, or other traits. Our study was also not designed to test the social contagion model, despite its importance within the peer effects literature. Future research should examine the extent to which students adopt peer or classroom norms (i.e., high expectations) and how that may influence academic achievement. 
There were also limitations in our data collection and instruments. The social network survey limited students to five responses to reduce the cognitive demands for young children but future studies should consider using a roster list of students for children to choose from and identify peers. Such an approach can provide a fuller picture of children’s classroom networks. Lastly, in surveying students about peers only in the spring, we had to assume that these were the same peers that students sought help from throughout the year. Our rationale for spring was students would have had a longer period to know and interact with each other, thus allowing us to examine more stable peer networks. However, future studies should survey children in the fall and spring to capture changes in relationships. The extent to which changes in peer networks with the same year and class can impact student achievement is important in deciding the level of structure and input from teachers needed to support peer activities.

\section{Conclusion}

Despite the limitations in this study, our findings provide further support that young children's reading achievement is associated with the average level of reading skills exhibited by the peers they report talking to or seeking help from, especially for struggling readers. In addition, this is one of the largest studies to directly survey young children about their reading preferences and peer networks across multiple classrooms, schools, and districts. In examining these peer network patterns, this study provides a deeper understanding of the mechanisms by which peers may influence the achievement and outcomes of children in schools. Overall, the results provide educators with a more informed view of how peer relationships form and may be leveraged within classrooms to improve learning and achievement for all children. 


\section{References}

Achieve Inc. (2005). Rising to the challenge: Are high school graduates prepared for college and work? Washington, DC: Author.

Altermatt, E. R., \& Pomerantz, E. M. (2003). The development of competence-related and motivational beliefs: An investigation of similarity and influence among friends. Journal of Educational Psychology, 95, 111-123.

Altermatt, E. R., \& Pomerantz, E. M. (2005). The implications of having high-achieving versus low-achieving friends: A longitudinal analysis. Social Development, 14(1), 61-81.

Azmitia, M. (1988). Peer interaction and problem solving: When are two heads better than one? Child Development, 59, 87-96.

Bandura, A. (1977). Social learning theory. Englewood Cliffs, NJ: Prentice Hall.

Bandura, A. (1986). Social foundations of thought and action: A social cognitive theory. Englewood Cliffs, NJ: Prentice-Hall.

Bruner, J. S. (1975). From communication to language: A psychological perspective. Cognition, 3, 255-287.

Calvo-Armengol, A., Patacchini, E., \& Zenou, Y. (2009). Peer effects and social networks in education. Review of Economic Studies, 76(4), 1239-1267.

Cairns, R. B., Cairns, B. D., Neckerman, H. J., Gest, S. D., \& Gariépy, J.-L. (1988). Social networks and aggressive behavior: Peer support or peer rejection? Developmental Psychology, 24, 815-823.

Chall, J. S., \& Jacobs, V. A. (2003). Poor children's fourth-grade slump. American Educator, 27(1), 14-15, 44.

Christakis, N. A., \& Fowler, J. H. (2013). Social contagion theory: Examining dynamic social 
networks and human behavior. Statistics in Medicine, 32(4), 556-577.

Daly, A. J. (2010). Social network theory and educational change. Cambridge, MA: Harvard Education Press.

DeLay, D., Hanish, L. D, Martin, C. L., \& Fabes, R. A. (2016). Peer effects on Head Start children’s preschool competency. Developmental Psychology, 52(1), 58-70.

Dubeck, M. M., \& Gove, A. (2015). The early grade reading assessment (EGRA): Its theoretical foundation, purpose, and limitations. International Journal of Educational Development, 40, 315-322.

Ellis, S., \& Rogoff, B. (1986). Problem solving in children's management of instruction. In E. Mueller \& C. Cooper (Eds.), Process and outcome in peer relationships (pp. 301-326). New York: Academic Press.

Edmonds, M. S., Vaughn, S., Wexler, J., Reutebuch, C., Cable, A., ... Schnakenberg, J. W. (2009). A synthesis of reading interventions and effects on reading comprehension outcomes for older struggling readers. Review of Educational Research, 79(1), 262-300.

Entwisle, D. R., \& Alexander, K. L. (1994). Winter setback: The racial composition of schools and learning to read. American Sociological Review, 59(3), 446-460.

Fletcher, J. (2010). Spillover effects of inclusion of classmates with emotional problems in early elementary school. Journal of Policy Analysis and Management, 29, 69-83.

Frank, K. A., Zhao, Y., \& Borman, K. (2004). Social capital and the diffusion of innovations within organizations: The case of computer technology in schools. Sociology of Education, 77, 148-171.

Frank, K. A., Muller, C., Schiller, K., Riegle-Crumb, C., Mueller, A. S., Crosnoe, R., \& Pearson, J. (2008). The social dynamics of mathematics coursetaking in high school. Journal of 
Sociology, 113(6), 1645-1696.

Fuchs, D., Fuchs, L. S., \& Burish, P. (2000). Peer-assisted learning strategies: An evidencebased practice to promote reading achievement. Learning Disabilities Research \& Practice, 15(2), 85-91.

Fuchs, D., Fuchs, L. S., Mathes, P. G., \& Simmons, D. C. (1997). Peer-assisted learning strategies: Making classrooms more responsive to diversity. American Educational Research Journal, 34, 174-206.

Fuchs, D., Fuchs, L. S., Thompson, A., Svenson, E.,...Saenz, L. (2000). Peer-assisted learning strategies in reading: Extensions for kindergarten, first grade, and high school. Remedial and Special Education, 22(1), 15-21.

Fujimoto, K., Unger, J. B., \& Valente, T. W. (2012). A network method of measuring affiliationbased peer influence: Assessing the influences of teammates’ smoking on adolescent smoking. Child Development, 83(2), 442-451.

Goldring, R., Gray, L., Bitterman, \& Broughman, S. (2013). Characteristics of public and private elementary and secondary school teachers in the United States: Results from the Schools and Staffing Survey. Washington, DC: National Center for Education Statistics.

Good, R. H., Kaminski, R. A., Cummings, E., Dufour-Martel, C., Petersen, K., Powell-Smith, K..., Wallin, J. (2011). DIBELS Next assessment manual. Dynamic Measurement Group.

Greenwood, C. R., Delquadria, J. C., \& Hall, R. V. (1989). Longitudinal effects of classwide peer tutoring. Journal of Educational Psychology, 81, 371-383.

Hanish, L. D., Martin, C. L., Fabes, R. A., Leonard, S., \& Herzog, M. (2005). Exposure to externalizing peers in early childhood: Homophily and peer contagion processes. Journal of Abnormal Child Psychology, 33(3), 267-281. 
Hannenman, R. A., \& Riddle, M. (2011). Concepts and measures of basic network analysis. In J. Scott \& P. Carrington (Eds.), The Sage Handbook of Social Network Analysis (pp. 341369). Thousand Oaks, CA: Sage.

Hanushek, E. A., Kain, J. F., Markman, J. M., \& Rivkin, S. G. (2003). Does peer ability affect student achievement? Journal of Applied Psychometrics, 18, 527-544.

Harris, D. N. (2010). How do school peers influence student educational outcomes? Theory and evidence from economics and other social sciences. Teachers College Record, 112(4), 1163-1197.

Henry, G. T., \& Rickman, D. K. (2007). Do peers’ influence children’s skill development in preschool? Economics of Education Review, 26, 100-112.

Hong, G., Corter, C., Hong, Y., \& Pelletier, J. (2012). Differential effects of literacy instruction time and homogenous ability group in kindergarten classroom: Who will benefit? Who will suffer? Educational Evaluation and Policy Analysis, 34(1), 69-88.

Hoxby, C. M., \& Weingarth, G. (2005). Taking race out of the equation: School reassignment and the structure of peer effects. Unpublished manuscript.

Jencks, C., \& Mayer, S. E. (1990). The social consequences of growing up in a poor neighborhood. In L. E. Lynn, Jr., \& Michael G. H. McGeary (Eds.), Inner city poverty in the United States (pp. 111-186). Washington, DC: National Academy Press.

Justice, L. M., Petscher, Y., Schatschneider, C., \& Mashburn, A. (2011). Peer effects in preschool classrooms: Is children's language growth associated with their classmates' skills. Child Development, 82(6), 1768-1777.

Justice, L. M., Logan, J. A. R., Lin, T-J., \& Kaderavek, J. N. (2014). Peer effects in early childhood education: Testing the assumptions of special-education inclusion. 
Psychological Science, 25(9), 1722-1729.

Kaminski, R., Cummings, K. D., Powell-Smith, K. A., Good, R. H. (2008). Best Practices in Using Dynamic Indicators of Basic Early Literacy Skills for Formative Assessment and Evaluation. In A. Thomas \& J. Grimes (Eds.), Best Practices in School Psychology V (pp.1181-1203). Bethesda, MD: National Association of School Psychologists.

Kamil, M. L. (2003). Adolescents and literacy: Reading for the 21st century. Washington, DC: Alliance for Excellent Education.

Kandel, D. B. (1978). Homophily, selection, and socialization in adolescent friendships. American Journal of Sociology, 84, 427-436.

Karabenick, S. A. \& Newman, R. S. (Eds.). (2006). Help seeking in academic settings: Goals, groups, and contexts. Mahwah, NJ: Erlbaum.

Kim, J. S., Guryan, J., White, T. G., Quinn, D. M., Capotosto, L., \& Kingston, H. C. (2016). Delayed effects of a low-cost and large-scale summer reading intervention on elementary school children's reading comprehension. Journal of Research on Educational Effectiveness, 9(Supplement), 1-22.

Kimelberg, S. D., \& Billingham, C. M. (2012). Attitudes toward diversity and the school choice process: Middle-class parents in a segregated urban public school district. Urban Education, 48(2), 198-231.

Kindermann, T. A. (2007). Effects of naturally existing peer groups on changes in academic engagement in a cohort of sixth graders. Child Development, 78, 1186-1203.

Lemons, C. J., Fuchs, D., Gilbert, J. K., \& Fuchs, L. S. (2014). Evidence-based practices in a changing world: Reconsidering the counterfactual in educational research. Educational Researcher, 43(5), 242-252. 
Maheady, L., Harper, G. F., \& Sacca, M. K. (1988). Peer-mediated instruction: A promising approach to meeting the diverse needs of LD adolescents. Learning Disability Quarterly, $11,108-113$.

Marsden, P. V. (2011). Survey methods for network data. In J. Scott \& P. Carrington (Eds.), The Sage Handbook of Social Network Analysis (pp. 370-388). Thousand Oaks, CA: Sage.

Martin, C. L., Kornienko, O., Schaefer, D. R., Hanish, L. D., Fabes, R. A., \& Goble, P. (2013). The role of sex peers and gender-typed activities in young children's peer affiliative networks: A longitudinal analysis of selection and influence. Child Development, 84(3), 921-937.

Masburn, A. J., Justice, L. M., Downer, J. T., \& Pianta, R. C. (2009). Peer effects on children’s language achievement during pre-kindergarten. Child Development, 80(3), 686-702.

Meijs, N., Cillessen, A. H. N., Scholte, R. H. J., Segers, E., \& Spijkerman, R. (2010). Social intelligence and academic achievement as predictors of adolescent popularity. Journal of Youth and Adolescence, 39, 62-72.

National Center for Education Statistics (2013). The national's report card: A first look 2013 mathematics and reading (NCES 2014-451). Institute of Education Sciences, U.S. Department of Education, Washington, D.C.

Pyle, D., Pyle, N., Lignugaris-Kraft, B., Duran, L., \& Akers, J. (2016). Academic effects of peermediated interventions with English language learners: A research synthesis. Review of Educational Research, Online First.

Roda, A., \& Wells, A. S. (2013). School choice policies and racial segregation: Where white parents’ good intentions, anxiety, and privilege collide. American Journal of Education, 119(2), 261-293. 
Ryan, A. M. (2001). The peer group as a context for the development of young adolescent motivation and achievement. Child Development, 72, 1135-1150.

Ryan, A. M., \& Shim, S. S. (2012). Changes in help seeking from peers during early adolescence: Associations with changes in achievement and perceptions of teachers. Journal of Educational Psychology, 104(4), 1122-1134.

Sacerdote, B. (2001). Peer effects with random assignment: Results for Dartmouth roommates. Quarterly Journal of Economics, 116, 681-704.

Schechter, C., \& Bye, B. (2007). Preliminary evidence for the impact of mixed-income preschools on low-income children's language growth. Early Childhood Research Quarterly, 22, 137-146.

Schunk, D. H. (1987). Peer models and children's behavioral change. Review of Educational Research, 57(2), 149-174.

Schunk, D. H. (1998). Teaching elementary students to self-regulate practice of mathematical skills with modeling. In D. H. Schunk \& B. J. Zimmerman (Eds.), Self-regulated learning, from teaching to self- reflective practice (pp. 137-159). NY: Guilford Press.

Schunk, D. H., \& Hanson, A. R. (1989). Self-modeling and children’s cognitive skill learning. Journal of Educational Psychology, 81, 155-163.

Scott, J., \& Carrington, P. J. (2011). The Sage handbook of social network analysis. Thousand Oaks, CA: Sage Publications.

Smith, J. A., McPherson, M., \& Smith-Lovin, L. (2014). Social distance in the United States: Sex, race, religion, and education homophily among confidants, 1985-2004. American Sociological Review, 79(3), 432-456.

Snow, C. E., \& Biancarosa, G. (2003). Adolescent literacy and the achievement gap: What do we 
know and where do we go from here? New York: Carnegie Corporation of New York.

StataCorp. (2013). Stata: Release 13. Statistical Software. College Station, TX: StataCorp LP.

Vu, J. A., \& Locke, J. J. (2014). Social network profiles of children in early elementary school classrooms. Journal of Research in Childhood Education, 28(1), 69-84.

Vygotsky, L. S. (1978). Mind in society. Cambridge, MA: Harvard University Press.

Wood, D. (1980). Teaching the young child: Some relationships between social interaction, language, and thought. In D. Olson (Ed.), The social foundations of language and thought (pp. 280-298). New York: Norton.

Wood, D., Bruner, J. S., \& Ross, G. (1976). The role of tutoring in problem solving. Journal of Child Psychology and Psychiatry, 17(2), 89-100.

Zimmer, R. W., \& Toma, E. F. (2000). Peer effects in private and public schools across countries. Journal of Policy Analysis and Management, 19, 75-92. 
Table 1

Summary of student and teacher characteristics

\begin{tabular}{|c|c|c|c|c|}
\hline & $n$ & $\%$ & Mean & $S D$ \\
\hline \multicolumn{5}{|l|}{ Student Characteristics } \\
\hline \multicolumn{5}{|l|}{ Gender } \\
\hline Male & 2,056 & 49.6 & & \\
\hline Female & 2,088 & 50.4 & & \\
\hline \multicolumn{5}{|l|}{ Race } \\
\hline Black & 1,881 & 45.4 & & \\
\hline Hispanic / Latino & 947 & 22.9 & & \\
\hline White & 612 & 14.8 & & \\
\hline Other & 701 & 16.9 & & \\
\hline \multicolumn{5}{|l|}{ English language learner } \\
\hline No & 3,517 & 84.7 & & \\
\hline Yes & 637 & 15.3 & & \\
\hline \multicolumn{5}{|l|}{ Free or Reduced Price Lunch } \\
\hline No & 792 & 19.0 & & \\
\hline Yes & 3,379 & 81.0 & & \\
\hline \multicolumn{5}{|l|}{ Grade } \\
\hline Second & 2,447 & 58.1 & & \\
\hline Third & 1,768 & 42.0 & & \\
\hline \multicolumn{5}{|l|}{ Literacy Skills } \\
\hline Grade 2: Fall DIBELS & 2,266 & & 158.3 & 76.9 \\
\hline Grade 2: Spring DIBELS & 2,341 & & 259.8 & 108.8 \\
\hline Grade 3: Fall DIBELS & 1,578 & & 236.9 & 123.4 \\
\hline Grade 3: Spring DIBELS & 1,637 & & 334.5 & 131.2 \\
\hline \multicolumn{5}{|l|}{ Teacher Characteristics } \\
\hline \multicolumn{5}{|l|}{ Gender } \\
\hline Female & 270 & 94.4 & & \\
\hline Male & 16 & 5.6 & & \\
\hline \multicolumn{5}{|l|}{ Race } \\
\hline Black & 57 & 19.9 & & \\
\hline Hispanic & 4 & 1.4 & & \\
\hline Native American & 16 & 5.6 & & \\
\hline White & 209 & 73.1 & & \\
\hline Other & 1 & 0.4 & & \\
\hline Age & 286 & & 38.2 & 11.8 \\
\hline \multicolumn{5}{|l|}{ Education } \\
\hline Barron Undergraduate Ranking & 251 & & 4.0 & 1.1 \\
\hline Class Size & 286 & & 14.3 & 4.2 \\
\hline
\end{tabular}

Note. DIBELS = Dynamic Indicators of Basic Early Literacy Skills;

Barron ranking: 1 = most competitive, $6=$ least competitive 
Table 2

Summary of student and peer reading levels by fall DIBELS quartile and grade

\begin{tabular}{crrrrrr}
\hline $\begin{array}{c}\text { Grade } 2 \\
\text { Quartile }\end{array}$ & $\begin{array}{c}\text { Student } \\
\text { Mean }\end{array}$ & SD & Meer & SD & Difference & \multicolumn{1}{c}{$t$} \\
\hline 1 & 57.5 & 38.1 & 157.2 & 58.5 & -99.8 & -32.0 \\
2 & 138.6 & 14.4 & 173.0 & 51.5 & -34.4 & -14.2 \\
3 & 185.7 & 14.0 & 182.7 & 52.6 & 3.0 & 1.2 \\
4 & 254.1 & 35.0 & 193.0 & 54.1 & 61.1 & 21.1 \\
Overall & 158.3 & 76.9 & 176.5 & 55.8 & -18.2 & -9.1 \\
\hline Grade 3 & & & & & & \\
Quartile & & & & & & \\
1 & 74.3 & 47.5 & 240.6 & 91.2 & -166.3 & -28.4 \\
2 & 204.6 & 26.3 & 248.8 & 84.6 & -44.3 & -8.8 \\
3 & 278.8 & 21.5 & 262.9 & 74.5 & 15.8 & 3.6 \\
4 & 390.9 & 67.9 & 320.0 & 101.2 & 70.9 & 10.7 \\
Overall & 236.9 & 123.4 & 269.1 & 93.8 & -32.3 & -7.8 \\
\hline
\end{tabular}

Note: DIBELS = Dynamic Indicators of Basic Early Literacy Skills 
Table 3

Summary of indegree frequency and student reading achievement

\begin{tabular}{ccrrr}
\hline Grade 2 & & \multicolumn{3}{c}{ DIBELS Spring Scores } \\
\cline { 3 - 5 } Indegree & Percent & Mean & SD & $\mathrm{N}$ \\
\hline 0 & 16.0 & 224.4 & 111.6 & 360 \\
1 & 21.9 & 238.5 & 108.6 & 493 \\
2 & 21.2 & 258.0 & 105.2 & 478 \\
3 & 14.0 & 267.3 & 102.3 & 314 \\
4 & 10.8 & 295.6 & 94.3 & 243 \\
5 & 6.3 & 284.7 & 99.9 & 141 \\
6 & 4.0 & 306.1 & 103.1 & 89 \\
$7+$ & 5.9 & 325.4 & 94.6 & 132 \\
\hline Grade 3 & & & & \\
Indegree & & & & \\
0 & 15.3 & 298.8 & 148.2 & 231 \\
1 & 25.6 & 307.6 & 127.7 & 387 \\
2 & 20.5 & 321.8 & 126.4 & 310 \\
3 & 16.4 & 363.6 & 105.5 & 248 \\
4 & 9.7 & 370.6 & 111.2 & 147 \\
5 & 5.4 & 391.9 & 113.5 & 82 \\
6 & 3.0 & 410.4 & 116.6 & 46 \\
$7+$ & 4.0 & 446.6 & 103.7 & 60 \\
\hline
\end{tabular}

Note: DIBELS = Dynamic Indicators of Basic Early Literacy Skills 
Table 4

Regression models predicting the relationship between child spring literacy skills and peer reading skills in Grade $2(n=2,447)$

\begin{tabular}{|c|c|c|c|c|}
\hline & $\begin{array}{c}(1) \\
B(S E)\end{array}$ & $\begin{array}{c}(2) \\
B(S E)\end{array}$ & $\begin{array}{c}(3) \\
B(S E)\end{array}$ & $\begin{array}{c}(4) \\
B(S E)\end{array}$ \\
\hline Peer DIBELS (fall) & $\begin{array}{c}0.021 \\
(0.034)\end{array}$ & $\begin{array}{c}0.005 \\
(0.033)\end{array}$ & $\begin{array}{c}0.023 \\
(0.025)\end{array}$ & $\begin{array}{l}0.163^{* * *} \\
(0.046)\end{array}$ \\
\hline Child DIBELS (fall) & $\begin{array}{l}1.082^{* * *} \\
(0.024)\end{array}$ & $\begin{array}{l}1.061^{* * *} \\
(0.026)\end{array}$ & $\begin{array}{l}1.058^{* * *} \\
(0.019)\end{array}$ & $\begin{array}{l}1.218^{* * *} \\
(0.047)\end{array}$ \\
\hline Female & & $\begin{array}{l}11.144^{* * *} \\
(2.709)\end{array}$ & $\begin{array}{l}13.708^{* * *} \\
(2.356)\end{array}$ & $\begin{array}{l}13.812^{* * *} \\
(2.343)\end{array}$ \\
\hline ELL & & $\begin{array}{r}-11.962^{*} \\
(6.043)\end{array}$ & $\begin{array}{c}-12.485^{* *} \\
(4.433)\end{array}$ & $\begin{array}{c}-12.003^{* *} \\
(4.439)\end{array}$ \\
\hline Free Lunch & & $\begin{array}{l}-3.755 \\
(4.544)\end{array}$ & $\begin{array}{l}-4.486 \\
(3.537)\end{array}$ & $\begin{array}{l}-5.404 \\
(3.523)\end{array}$ \\
\hline Hispanic & & $\begin{array}{l}-9.034 \\
(6.341)\end{array}$ & $\begin{array}{c}4.755 \\
(5.250)\end{array}$ & $\begin{array}{c}4.483 \\
(5.261)\end{array}$ \\
\hline Black & & $\begin{array}{l}-2.331 \\
(5.476)\end{array}$ & $\begin{array}{c}0.762 \\
(4.297)\end{array}$ & $\begin{array}{c}0.525 \\
(4.295)\end{array}$ \\
\hline Other & & $\begin{array}{r}-11.855 \\
(6.434)\end{array}$ & $\begin{array}{l}-3.209 \\
(5.345)\end{array}$ & $\begin{array}{l}-3.173 \\
(5.359)\end{array}$ \\
\hline Child $\times$ Peer DIBELS (fall) & & & & $\begin{array}{l}-0.0009^{* * *} \\
(0.0001)\end{array}$ \\
\hline Intercept & $\begin{array}{l}84.646^{* * *} \\
(7.647)\end{array}$ & $\begin{array}{l}95.414^{* * *} \\
(9.758)\end{array}$ & $\begin{array}{l}86.002^{* * *} \\
(7.172)\end{array}$ & $\begin{array}{l}62.432^{\text {**** }} \\
(9.512)\end{array}$ \\
\hline Classroom fixed effects? & No & No & Yes & Yes \\
\hline
\end{tabular}


Table 5

Regression models predicting the relationship between child spring literacy skills and peer reading skills in Grade $3(n=1,768)$

\begin{tabular}{|c|c|c|c|c|}
\hline & $\begin{array}{c}(1) \\
B(S E)\end{array}$ & $\begin{array}{c}(2) \\
B(S E)\end{array}$ & $\begin{array}{c}(3) \\
B(S E)\end{array}$ & $\begin{array}{c}(4) \\
B(S E)\end{array}$ \\
\hline Peer DIBELS (fall) & $\begin{array}{l}-0.040 \\
(0.034)\end{array}$ & $\begin{array}{l}-0.051 \\
(0.034)\end{array}$ & $\begin{array}{c}0.016 \\
(0.022)\end{array}$ & $\begin{array}{l}0.178^{* * *} \\
(0.039)\end{array}$ \\
\hline Child DIBELS (fall) & $\begin{array}{l}0.915^{* * *} \\
(0.034)\end{array}$ & $\begin{array}{l}0.903^{* * *} \\
(0.036)\end{array}$ & $\begin{array}{l}0.941^{* * *} \\
(0.015)\end{array}$ & $\begin{array}{l}1.126^{* * *} \\
(0.041)\end{array}$ \\
\hline Female & & $\begin{array}{c}8.402^{*} \\
(3.536)\end{array}$ & $\begin{array}{l}9.552^{* *} \\
(3.243)\end{array}$ & $\begin{array}{l}8.863^{* *} \\
(3.207)\end{array}$ \\
\hline ELL & & $\begin{array}{l}-9.151 \\
(6.712)\end{array}$ & $\begin{array}{r}-10.528 \\
(5.878)\end{array}$ & $\begin{array}{r}-10.846 \\
(5.829)\end{array}$ \\
\hline Free Lunch & & $\begin{array}{l}-5.450 \\
(5.203)\end{array}$ & $\begin{array}{l}-8.887 \\
(4.880)\end{array}$ & $\begin{array}{l}-9.133 \\
(4.845)\end{array}$ \\
\hline Hispanic & & $\begin{array}{r}-19.314^{*} \\
(9.402)\end{array}$ & $\begin{array}{c}2.209 \\
(7.459)\end{array}$ & $\begin{array}{c}0.989 \\
(7.376)\end{array}$ \\
\hline Black & & $\begin{array}{c}-27.551^{* * *} \\
(7.225)\end{array}$ & $\begin{array}{r}-13.768^{*} \\
(5.426)\end{array}$ & $\begin{array}{c}-15.803^{* *} \\
(5.334)\end{array}$ \\
\hline Other & & $\begin{array}{l}-2.266 \\
(7.795)\end{array}$ & $\begin{array}{c}3.757 \\
(6.755)\end{array}$ & $\begin{array}{c}2.454 \\
(6.676)\end{array}$ \\
\hline Child $\times$ Peer DIBELS (fall) & & & & $\begin{array}{l}-0.0007^{* * *} \\
(0.0001)\end{array}$ \\
\hline Intercept & $\begin{array}{l}127.325^{* * *} \\
(12.282)\end{array}$ & $\begin{array}{l}151.009^{* * *} \\
(17.448)\end{array}$ & $\begin{array}{c}115.534^{* * *} \\
(8.949)\end{array}$ & $\begin{array}{l}77.848^{* * *} \\
(11.607)\end{array}$ \\
\hline Classroom fixed effects? & No & No & Yes & Yes \\
\hline
\end{tabular}



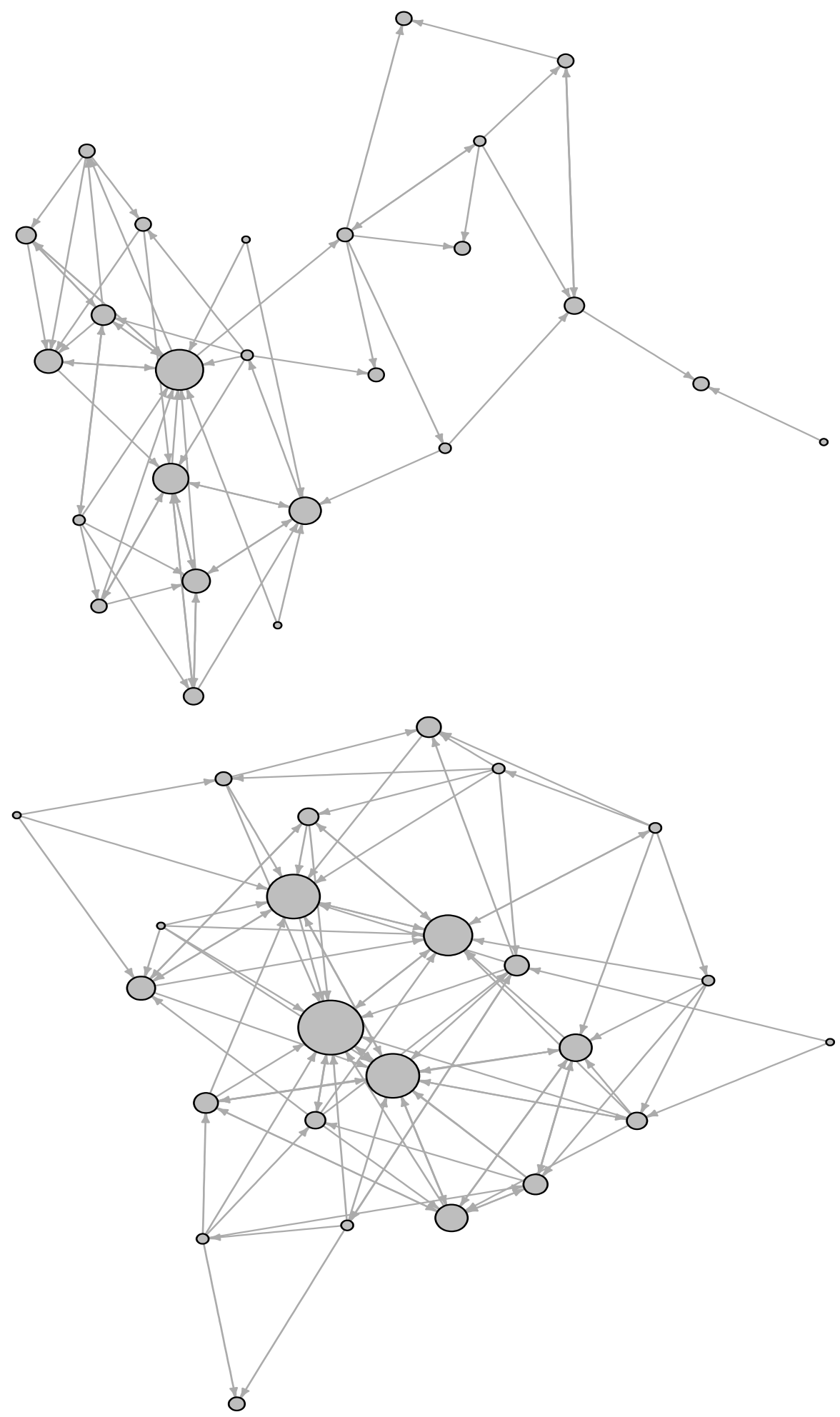

Figure 1. Examples of social networks from two classrooms. Node size and arrow direction indicate students that others report seeking about reading. 


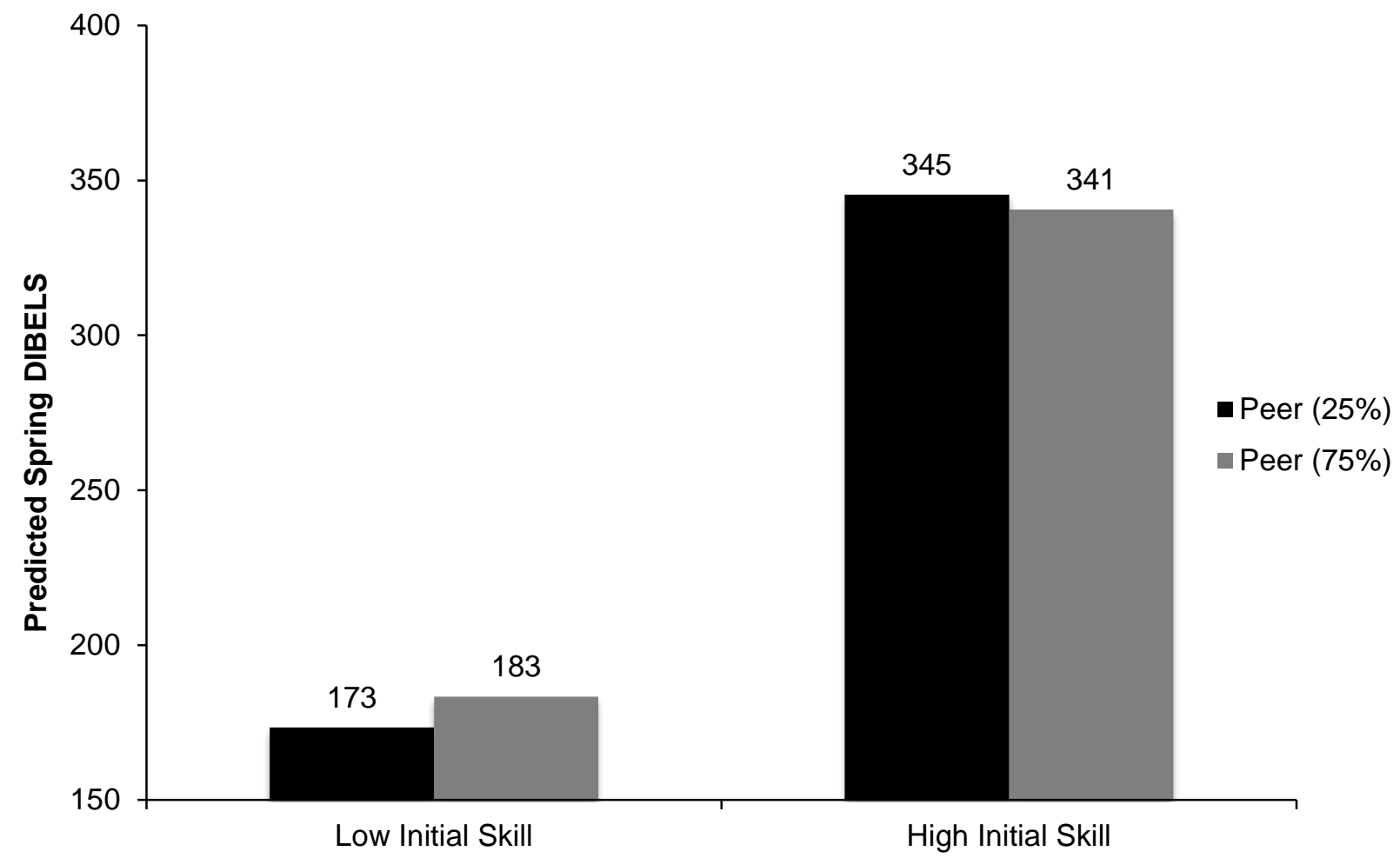

Figure 2. The interaction between children's initial (fall) DIBELS scores (one standard deviation above and below the mean) and peers' DIBELS scores for grade two ( $25^{\text {th }}$ and $75^{\text {th }}$ percentile) when predicting children's spring DIBELs scores. Differences are significant only for low initial students $(\mathrm{p}<.05)$. 


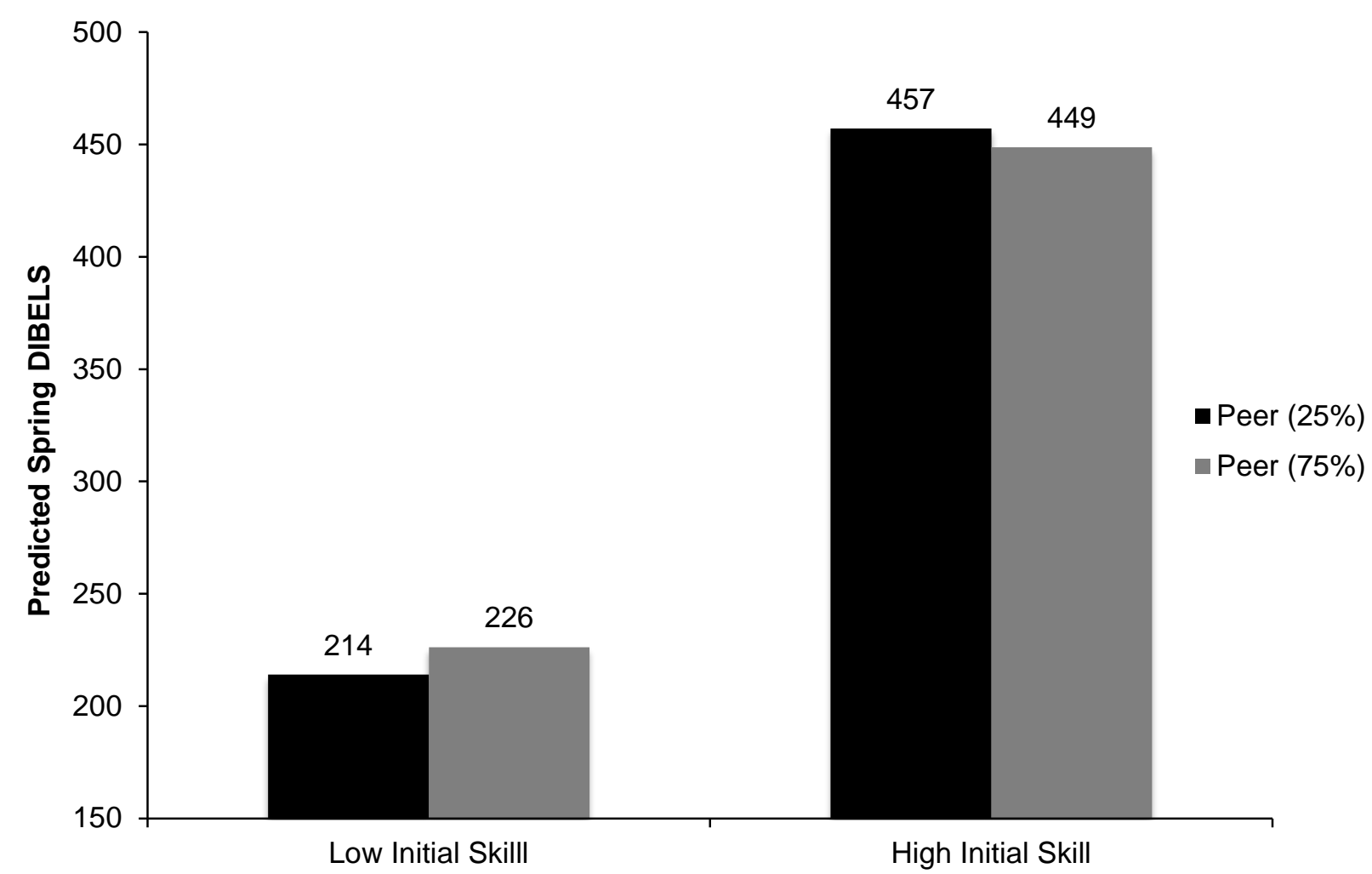

Figure 3. The interaction between children's initial (fall) DIBELS scores (one standard deviation above and below the mean) and peers' DIBELS scores for grade three ( $25^{\text {th }}$ and $75^{\text {th }}$ percentile) when predicting children's spring DIBELs scores. Differences are significant for both groups (p $<.05)$. 